\title{
Servitization within manufacturing operations: An exploration of the impact to facilities practices
}

\begin{abstract}
Servitization is a growing area of interest amongst practitioners, policy makers and academics, and much is still to be learnt about its adoption in practice. This paper makes a contribution to this debate by identifying the key facilities practices that successfully servitizing manufacturers appear to be deploying and the underlying rationale behind their configuration. Although these are preliminary findings from a longer-term research programme, this short communication seeks to highlight implications to manufacturing professionals and organisations who are considering the servitization of their operations.
\end{abstract}

\section{Introduction}

Services offer a growing source of revenue and resilience against economic downturns for many industrial companies. In the aerospace sector, for example, engine manufacturers such as RollsRoyce, General Electric and Pratt \& Whitney, all offer some form of performance-based service contracts with commercial airlines. Such contracts provide the airline operator with fixed engine maintenance costs over an extended period of time of typically ten years. Many other western companies are also following such servitization strategies, especially those already with a high installed base of complex equipment.

Servitization can however impact the entire operations of a manufacturer. Successfully supporting such advanced services will demand technologies and practices that are subtly different to those associated with conventional production [1]. Our goal is to understand these differences and their underpinning rationale. This complements the broader research inititives in this field (see for example; Vargo \& Lusch [2], Spohrer et al [3]) To achieve this we have embarked upon a large and far reaching research programme to study the practices of manufacturers who are leading in the adoption of servitization. In this paper we deal with the common facilities practices for their form and location, and reflect on how of these differ to the practices typically associated with conventional production operations.

Our intention in this short communication is to simultaneously contribute to the current debate around servitization in the research community, and improve awareness amongst manufacturers to the consequences of supporting advanced services. To realise this aim, the paper is organised to first summarise the typical facilities practices that occur in conventional production operations. Then an overview is given of the research design for this study is presented. Finally, our findings associated with servitization and new facilities practices are illustrated, before drawing together our conclusions.

\section{Generic facilities practices within conventional production operations}

In attempting to generalise the practices in terms of the location and structure of production operation facilities, clearly there are many forms that such operations can take. However, clues do exist as to the popular characteristics of such facilities (see for example; Ford [4], Skinner [5], Womack [6] and Baines et al [7]). Such authors highlight that although production operations can take differing forms (usually based around the volume and variety of products they produce, eg: 
project, Jobbing, Batch, Mass, and Process) there are strong similarities in facilities practices. They all seek to exploit economies of scale and resource availability. Hence, the over-ridding tendency is for centralised facilities, where people and equipment are located in one place, and production materials are transferred to the location. Current examples in modern operation include the Jaguar car plant at Castle Bromwich in Birmingham which produce Jaguar XK and XF ranges; the Rolls Royce aero engine facilities at Derby producing the Trent 800, 900 and 1000; and the M.A.N. facility in Munich producing a range of trucks and buses.

This rationale is illustrated in the practices of manufacturing offshoring. The literature gives a number of examples where companies have relocated their facilities to exploit low labour cost in less developed economies. Such decisions are influenced by factors such as availability of natural resources (eg: materials and energy), market access, political environment and government incentives. However, the overriding concern appears as access to labour, and leads to the development of large and centralised factories that exploit scale and resources. The question that then arises, is how are such practices impacted when manufacturers seek to compete through a portfolio of advanced services which are coupled to their products?

\section{Research methodology}

Our purpose has been to understand the differences between the typical facilities practices in production operations and those followed by successful servitized manufacturers. In brief, our method has been to carry out in-depth and multi-disciplinary case-studies of manufacturers who are leading in the delivery of advanced product-centric services.

The data collection protocol was developed and conducted over a 15 month period and completed in October 2010. Semi-structured interviews were held with senior personnel in five multinational of Xerox (London), Caterpillar (Peoria, USA), Rolls-Royce (Derby), MAN (Swindon) and Alstom (Wolverhampton). Collectively these deal with the rail transport, aerospace, road transport, office products, and construction equipment sectors. The focus of the interviews was on the people, process and technologies that are used in the delivery of advanced product-centric services such as risk and revenue sharing contracts. These results were then compiled and cross-examined. At this stage, clear and compelling evidence emerged that the location and organisation of facilities in servitized manufacturers differs, to those of production operations, along with the rational explaining this difference. This evidence motivated the construction of this short communication.

\section{Facilities practices within servitized operations}

This section first summarises the facilities practices found in servitized operations, explains the principal business pressures driving these, and then presents an 'influence' diagram to illustrate the rationale and linking mechanism (see figure 1 ).

The emergent facilities practice: As manufacturers extend their portfolio of product-centric services, then they appear to adopt:

'Facilities that are located in close physically proximity to the customers operations and distributed geographically throughout these'.

Evidence of this appears in the operations across the organisations studied. For example, Caterpillar has an extensive geographic network of autonomous dealers, and these dealers themselves may 
have strategically placed depots close to the customer base. MAN is somewhat similar, again facilities are carefully located geographically such that they are physically close to their principal customer base. In the London region, for example, facilities are typically within a ten mile radius of the customer (the vehicle operator).

This situation is further demonstrated by Alstom who have designed and now support the Pendolino trains operated by Virgin Trains on the West Coast mainline routes in the UK. As part of supporting this advanced service, they subsequently took over the existing rail side maintenance and repair facilities which are regionally distributed across the network. They also have a similar contract for advanced services associated with the Northern Line of the London Underground. Here, they again they took over maintenance and repair facilities located at either end of the tube line and were previously owned by the underground operator. This is similar to Rolls-Royce Aerospace who has established facilities for Maintenance and Repair Operations (MRO), through joint ventures with major customers such as American, Singapore and Cathay, which are located close to the operational hubs of these airline customers.

The extent to which a manufacturer decentralises facilities appears dependent on the balance between delivering products and delivering services. If the company retains Original Equipment Manufacture then they may also retain a centralised production hub, as is the case with companies such as Rolls-Royce and Caterpillar. Such a hub appears to be less stainable as the balance of the company's business moves towards advanced services.

Underlying business pressures driving the facilities decision: Our case work has also illustrated that where a manufacturer sets out to adopt advanced services two sets of macro business pressures are incurred that help to explain their facilities practices. One set reflects the direct customer demands of a service offering and, in the case of advanced services, is concerned with measures of performance, availability and reliability. Performance is concerned with the extent to which the full capability of equipment is accessible, for example the power delivered by a gas-turbine as a percentage of that specified. Availability is typically measured as the extent of time that a product or asset is available for use, as a proportion of the scheduled availability. An example of this is Alstom where their contract with the train operator specifies the units of rolling stock that must be available and fully operable for typically $20 \mathrm{hrs}$ each day. Reliability is taken as a measure of meantime between in-service failures. The second principle pressure is from the host manufacturer, and is concerned with the resources required to deliver the service offering, and is typically measured as contract delivery cost.

Underlying relationship between practice and business pressures: The relationship between facilities practice and business pressures is captured in figure 1. This illustrates that there are three principal routes through which the practice has an impact.

When facilities are located in physically close to a customer's operations, and distributed geographically throughout these, then product/asset performance and availability is positively impacted because the manufacturer can respond faster. This may occur as both faster fault diagnostics and response to a problem. This is achieved because staff are more likely to be on-hand when or as a failure occurs, possibly witnessing a failure themselves, and so taking corrective actions more quickly and precisely. Examples of this in practice include Caterpillar, who is likely to hold 
maintenance personnel and critical spare parts for quarry trucks, on-site and in reserve and at large customer mines. Likewise, Alstom support their activities on the Northern Line of the London Underground through safety stock, at line side maintenance and repair facilities located at end-ofline termini.

Figure 1: Illustrating the relationship between the facilities practice and key performance measures for advanced services contracts

The proximity of facilities also positively impacts reliability, though principally through a process that centred on building strong relationships between the manufacturer and customer at the level of day-to-day operations. This is critical to a healthy communication process, which itself enables the manufacturer to witness and directly improve their understanding of the application and the way in which the user operates their product. This knowledge can be used to either arrange appropriate contingencies should failure occur (for e.g. knowing precisely where to locate stock reserves and so improving availability), and subsequently modifying the design of products so that they become more reliable. Indeed, it is this capability to improve product designs that provides manufacturers with a significant advantage over competitors who are more conventional service providers.

Although positioning facilities throughout the customers operations positively impacts performance, availability and reliability, the downside is that contract delivery costs also increase. Replicating facilities throughout a customer's network of operations is expensive and invariably means that manpower and equipment are duplicated and cannot be utilised to their fullest extent. For example, Froude Hofmann, faced an increase of costs in setting up a series of in-country MRO facilities to deliver its customer's service response requirements, which had to be offset by the generation of increase revenues from customers.

These facilities practices, and their implications on business performance, are moderated by other practices within the broader service delivery system. Key here are stock-holding policies, available resource capacity, capabilities in remote product sensing technologies, and design capabilities. As illustrated in figure 1, decisions about these other practices impact the consequences of the facilities practices in a number of ways. For example, large amounts of capacity and stock can help to compensate for a poorly located facility, similarly predictive technologies can give the manufacturer advanced warning of an impending issue with an assets performance.

\section{Concluding remarks and future research}

Our research indicates that facilities practice adopted by successfully servitizing manufactures differ to those in conventional production operations. Fundamentally this is because the business pressures and subsequent performance measures also differ. Production tends to focus on cost, quality and delivery, where as advanced services contracts centre on performance, availability, reliability and cost. These demand that a manufacturer is responsive, and to be responsive they have to question the concept of a centralised factory located to best exploit materials and resources. While in some instanced such facilities may be retained for the production of equipment, providing 
advanced services successfully appears to require additional facilities that are integrated throughout their customer operations.

Our future work will now take this as a hypothesis for further testing. However, we recognise that this will be mediated by other factors within the wider service delivery system. For example, vertical integration, condition monitoring technologies, and capacity decisions all appear to influence facilities practices. Our future work will therefore set out to understand some of these other factors in greater detail, and we will report on these in the near future.

\section{References}

1. Oliva R. \& Kallenberg R., (2003) "Managing the Transition from Products to Services", International Journal of Service Industry Management, Vol.14, No. 2, pp. 1 -10

2. Vargo S. \& Lusch R., (2004), "Evolving to a new dominant logic for marketing", Journal of Marketing, Vol. 68, pp. 1-17

3. Spohrer J, Maglio P, Bailey J \& Gruhl D, (2007), "Steps Towards a Science of Service Systems", Computer, January, PP71-77

4. Ford H., (1922), "My Life and Work", Kessinger Publishing.

5. Skinner W., (1985), "Manufacturing: The formidable competitive weapon", John Wiley \& sons

6. Womack, J., Jones, D and Roos, D., (1990), "The Machine that Changed the World", Maxwell MacMillan International.

7. Baines, T.S, Lightfoot, H., Peppard, J., Johnson, M., Tiwari, A., Shehab, E., and Swink, M. (2009), "Towards an operations strategy for product-centric servitization", International Journal of Operations and Production Management, 29, 5, PP494-519. 